addition, it is painful, often the surrounding parts are edematous and a history of syphilis (locomotor ataxia), leprosy or severe injury to the cord can be obtained.

Leprosy of the mutilating type presents after Raynaud's disease the most likely point of error. Leprosy, however, is not confined exclusively to the colored race; it frequently occurs in whites. Its trophic lesions may be formed on any point of the body; not necessarily on some certain toe. Other manifestations of the disease, on other regions of the body, will certainly be present to confirm a diagnosis; moreover, in mutilating leprosy, as in Raynaud's disease, there are preliminary manifestations of necrosis, as bullæ, macules or tubercles at the point of attack where destruction is sure to follow.

A tuherculous nlcer or suppurating corn between the toes could scarcely be mistaken for ainhum.

\section{TREATMENT AND PROGNOSIS.}

Treatment of the affection from a conservative standpoint is highly unsatisfactory. Most patients appear too late for conservative measures and only, as in my case, after the toe has nearly removed itself. In the early stages of the disorder, all observers are agreed that linear incision, curettage, excision or scarification of the constricting band is the indicated method of procedure. This, however, does not insure against a return of the malady. Salicylic acid in ointment ( 20 per cent.) may be applied to remove the horny layer of epithelium or this may be accomplished by wet dressings of Thiersch's solution; (saturated boric-salicylic acid aqueous solution). This will cleanse and relieve the parts from pain but is not of permanent benefit. When the disorder is of long standing or troublesome, the affected toes should be amputated. ${ }^{15}$

\section{REPORT OF CASE.}

Patient.-J. V., a negro, aged 24, referred to me by Dr. Thomas Kennedy, Shelbyville, Ind.

History.-Ten years ago he first noticed a crack or furrow on the inner side of his little toe, on the right foot. This crack increased in depth and about six years later the toe dropped off. On his left foot, the disease first appeared about four years ago and has been steadily progressing. The toe hangs only by a thread not larger than a number 12 French sound.

The inconvenience to the patient arises when he puts on or off his shoe, and it has become necessary for him to cut away the outer portion of the shoe.

Remarks.-The illustration perfectly portrays the enlargement and tumefaction of the ball-like toe beyond the constricted portion; also the increased amount of epithelium and cornification over both the right and left phalangeal joints. The patient is a native of Kentucky and no history of heredity was obtainable. He sought relief on account of the pain occasioned by a small ulcer on the plantar surface of the toe.

Amputation was of course advised and performed. Bleeding was slight, and healing occurred promptly without inconvenience.

330 Newton Claypool Building.

15. Other reports of cases and references which may be con suited are as follows: Pyle: Med. News, Phila., 1895, vol. 1xvi, p. 85-88. Ohmann-Dumesnil: Trans. Med. Soc. of Missouri, 1895, p. 124-137; and Medicine, Detroit, 1895, p. 202. Herrick: Phila. Med. Jour., 1898, vol. f, p. 246. Bass: Nashville Jour. of Med. and Surg., 1898, vol. clxxxiv, p. 201-206. Wolf: Amer. Jour. of Derm. and Genito-Urinary Disease, St. Louis, 1889, vol. iil, p. 3 byles: Iancet, Sept. 25, 1886, p. 576. Gould and Pyle: “Anomalies and Curiosities of Medicine," p. 828. Love: Gaillards Med. Jour., N. Y., 1883 , vol. $\times \times \times v$, p. 367 369. Heitzmann, Trans. Amer. Derm., Assoc., Chicago, 1881, vol. v, p. 49-51.
ETHYL CHLORID ANESTHESIA OF THE MEMBRANA TYMPANI AND EXTERNAL AUDITORY CANAL.

EDW. H. SCHHLD, M.D.

Assistant Surgeon Baltimore Eye, Ear and Throat Charity Hospital. Clinical Assistant Eye and Ear Department Johns Hopkins Hospltal Dispensary. BALTIMORE.

The otologist performs the different operations within the external auditory canal under various difficulties. His field of operation is usually at the bottom of this deep and tortuous canal; the operations, while brief, are ordinarily very painful so that the patient is very apt to jerk his head and throw out of position the operator's carefully adjusted illumination and field of observation, resulting possibly in injury to neighboring structures. For these reasons, let alone the more humane one of saving the patient suffering, some form of anesthetic is desirable or at times even necessary.

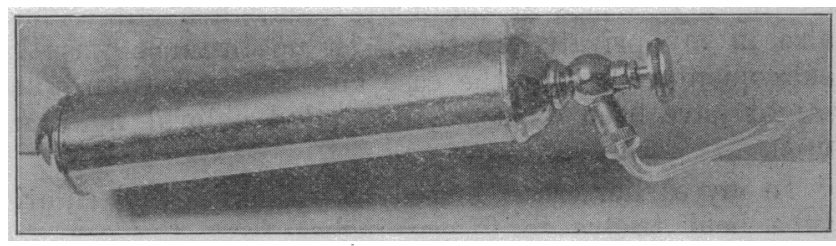

Figure 1.

Except in the case of young children or for delicate and complicated operations, the risk of a general anesthetic seems unwarranted. Solutions of cocain, or its equivalents, are absorbed but slowly and with difficulty by the skin surface of the canal and hypodermic injections are impractical for various and obvious reasons.

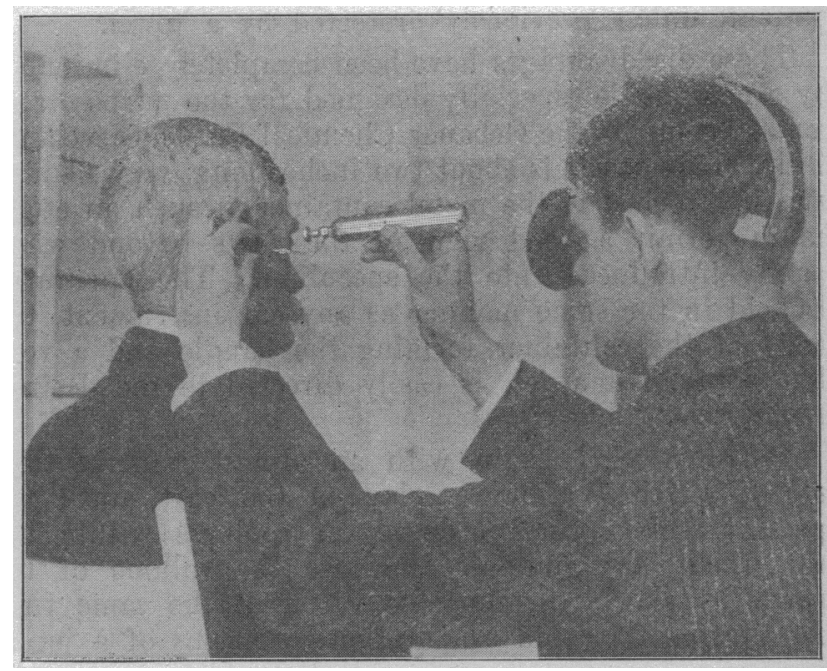

Figure 2.

A more suitable method of obtaining anesthesia in these cases is very desirable.

A very convenient and effieient means of producing local anesthesia is offered to us by freezing the part with ethyl chlorid; which, being always ready and quickly applied, forms an ideal method for office and clinical practice, since no time is lost in waiting for the anesthetic to be absorbed, as is the case with cocain solutions.

At first thought it might appear that the process of freezing may be fraught with danger and cause mis- 
chief to the structures of the middle or internal ear, or that the pain and discomfort incident to this process would offset the anesthetic qualities obtained, but practical experience has proven these fears unfounded.

My first experiment with this method was done on a patient suffering from a left facial paralysis of seven months' standing; the left ear was filled with exudate and almost deaf. The case is more fully reported by my friend, Dr. H. O. Reik, ${ }^{1}$ who suggested a paracentesis of the drum membrane on the affected side for the relief of the paralysis. A jet of ethyl chlorid was allowed to play into the canal for some seconds and the incision was then made. With the exception of a slight burning sensation due to the ethyl chlorid nothing was felt by the patient, who was a very nervous woman. She almost completely recovered from her facial paralysis and her hearing returned to normal. Encouraged by this success, which demonstrated the harmlessness of the procedure, I have since used this freezing method on every available case that presented itself during my service at the above mentioned clinics and also in my private practice. In no instance was the subsequent course of the case any different from what might have been expected, had ethyl chlorid not been used.

In my earlier cases, I used an ordinary ethyl chlorid tube held twelve to fifteen inches from the ear and allowed a jet of the liquid to play into the auditory canal through the previously inserted speculum. This had some disadvantages. One had no assurance that the drug actually reached the desired spot and hence anesthesia was sometimes imperfect; much liquid was wasted and more than necessary was injected, producing more or less pain and discomfort to the patient, and it was almost impossible to avoid getting some of the liquid on the face or even into the eye of the patient, unless previously protected by a towel.

These disadvantages have been completely eliminated by a new nozzle especially designed for the purpose and made for me by the Gebauer Chemical Co. of Cleveland, Ohio. This nozzle is about two inches long, very slender and is attached to the metal container at such an angle as to permit a good view of the parts beyond when partly introduced into the speculum. The apparatus is held in the same manner as any ear instrument, the body of the container forming the handle and a very fine spray, not a jet, is easily directed to the desired spot (Figs. 1 and 2).

In practice, I begin with an almost imperceptible spray, which I allow to play on the part, until the patient feels a certain degree of coolness within the ear, then very gradually increase the volume of the spray by slowly opening the valve, at the same time facilitating its rapid evaporation by means of a jet of air blown into the canal from a Politzer bag. With a little practice one soon learns to know how far it is necessary to carry the procedure in order to obtain a sufficient degree of anesthesia. For my part, I usually shut off the spray when the patient begins to complain of an aching sensation, then blow in a little more air and operate; the whole procedure taking but a few minutes. A minimum amount of ethyl chlorid is used and none wasted, an item of some importance when dealing with such an expensive drug.

In searching the literature on the subject I find

1. Reik: "The Relationship Petween Otitis Media (non-sup puration) and Facial Paralysis of the Refrigeratory Types. Trans. Am. Otological Soe., July, 1904, p. 376 . that Brieger2 mentions the use of etlyyl chlorid for similar purposes, but up to the present time have not been able to get access to his paper and am not familiar with his method of application.

In addition to the usual minor operations about the ear canal, such as paracentesis, incising furuncles, extracting polypi, etc., I have recently began to use ethyl chlorid in the manner above described as a preliminary to the application of Lucr's sound in the treatment of chronic otitis media and find it an ideal way to avoid pain, the one objectionable feature of that form of treatment. The results thus far seem to indicate a far greater percentage of markedly improved cases than I was able to obtain before introducing the preliminary freezing; however, further experience is necessary to more fully confirm this statement, and I shall take pleasure to report on the same at a future date.

449 East Twenty-second Street.

\section{THE TRANSMISSION OF DISEASE BY THE MOSQUITO.* \\ JOHIN R. TAYLOR, \\ Chief of the Laboratory of Las Animas Hospital. maVANA, CTIBA.}

The study of the life and habits of mosquitoes, not only in their adult stage, but in their cycle of development from the egg to the mosquito, is one of the most fascinating subjects that a person who has the time could possibly take up. Not only is the subject fascinating, but it is also of great importance that the life history of all species of mosquitoes should be understood, as they have been proved beyond a doubt to play a prominent part in the transmission of disease to human beings and animals, and more especially is this true of malaria, yellow fever and filariasis.

Mosquitoes belong to the order of Diptera, of the family Culicidee. They are differentiated from other insects which simulate them by, 1 . The piereing mouth. 2 . The scales on the veins of the wings. 3. The particular venation of the wings.

There are four stages in the life of the mosquito, the egg, larva, pupa and imago or winged insect. The early stage of the mosquito is always aquatic.

\section{EGGS.}

The eggs are deposited habitually on the surface of either natural or artificial collections of water. Occasionally, however, they may be laid on moist soil, or on grass above the water, and hatch out later when water reaches them. The eggs are laid in one of two ways, either singly, each egg lying on its side (Stegomyia fasciata); or in a boat-shaped mass containing from 200 to 400 eggs all glued together, each egg resting on its end (Culex). The eggs hatch out in from 12 hours to 2 days.

\section{LARV平.}

The larræ are eruciform, and easily recognized in the water by their wriggling morements. They have a disproportionately large head. The larva of the subfamily Anophetina habitually rest in a horizontal position at the surface of the water. Other species hold themselves in an oblique position, head downward, at the surface. The larvæ renain in the larval stage about a minimum of six days, but the duration may be much longer.

2. Brieger: Klinische Reitrige zur Ohrenbelkunde, 1896

* Read vefore the St. Louis Medical Society, 1904. 